\title{
Separation of the Formation Mechanisms of Residual Stresses in LPBF 316L
}

\author{
Alexander Ulbricht ${ }^{1, *}$, Simon J. Altenburg ${ }^{1}\left(\mathbb{D}\right.$, Maximilian Sprengel ${ }^{1}{ }^{\circledR}$, Konstantin Sommer ${ }^{1}$, \\ Gunther Mohr ${ }^{1,2}$, Tobias Fritsch ${ }^{1}{ }^{(0)}$, Tatiana Mishurova ${ }^{1}{ }^{10}$, Itziar Serrano-Munoz ${ }^{1}{ }^{\circledR}$, \\ Alexander Evans ${ }^{1}$, Michael Hofmann ${ }^{3}$ (D) and Giovanni Bruno ${ }^{1,4}$ \\ 1 Bundesanstalt für Materialforschung und -prüfung (BAM), Unter den Eichen 87, 12205 Berlin, Germany; \\ Simon.Altenburg@bam.de (S.J.A.); Maximilian.Sprengel@bam.de (M.S.); Konstantin.Sommer@bam.de (K.S.); \\ Gunther.Mohr@bam.de (G.M.); tobias.thiede@bam.de (T.F.); tatiana.mishurova@bam.de (T.M.); \\ Itziar.Serrano-Munoz@bam.de (I.S.-M.); alexander.evans@bam.de (A.E.); giovanni.bruno@bam.de (G.B.) \\ 2 Institute of Machine Tools and Factory Management, Chair of Processes and Technologies for Highly \\ Loaded Welds, Technische Universität Berlin, Straße des 17. Juni 135, 10623 Berlin, Germany \\ 3 Heinz Maier-Leibnitz Zentrum (MLZ), Technische Universität München, Lichtenbergstraße 1, \\ 85747 Garching, Germany; Michael.Hofmann@frm2.tum.de \\ 4 Institute of Physics and Astronomy, University of Potsdam, Karl-Liebknecht-Straße 24/25, \\ 14476 Potsdam, Germany \\ * Correspondence: alexander.ulbricht@bam.de; Tel.: +49-308-104-4140
}

Received: 29 July 2020; Accepted: 3 September 2020; Published: 14 September 2020

\begin{abstract}
Rapid cooling rates and steep temperature gradients are characteristic of additively manufactured parts and important factors for the residual stress formation. This study examined the influence of heat accumulation on the distribution of residual stress in two prisms produced by Laser Powder Bed Fusion (LPBF) of austenitic stainless steel 316L. The layers of the prisms were exposed using two different border fill scan strategies: one scanned from the centre to the perimeter and the other from the perimeter to the centre. The goal was to reveal the effect of different heat inputs on samples featuring the same solidification shrinkage. Residual stress was characterised in one plane perpendicular to the building direction at the mid height using Neutron and Lab X-ray diffraction. Thermography data obtained during the build process were analysed in order to correlate the cooling rates and apparent surface temperatures with the residual stress results. Optical microscopy and micro computed tomography were used to correlate defect populations with the residual stress distribution. The two scanning strategies led to residual stress distributions that were typical for additively manufactured components: compressive stresses in the bulk and tensile stresses at the surface. However, due to the different heat accumulation, the maximum residual stress levels differed. We concluded that solidification shrinkage plays a major role in determining the shape of the residual stress distribution, while the temperature gradient mechanism appears to determine the magnitude of peak residual stresses.
\end{abstract}

Keywords: additive manufacturing; Laser Powder Bed Fusion; LPBF; AISI 316L; online process monitoring; thermography; residual stress; neutron diffraction; X-ray diffraction; computed tomography

\section{Introduction}

In recent years, Additive Manufacturing (AM) has evolved from a method for rapid prototyping to a mature production process for certain parts in industries, such as the aerospace industry [1]. Among the different AM manufacturing techniques, Laser Powder Bed Fusion (LPBF) is an important technique for the production of net shaped metallic parts [2]. Early research conducted by Mercelis and 
Kruth [3] showed that metallic parts made by LPBF inherently contain residual stresses (RS). They had described two driving mechanisms for the formation of RS: the Temperature Gradient Mechanism (TGM) and the Solidification Shrinkage Mechanism (SSM). The two mechanisms are interlinked and their combined effect on RS in AM 316L is a topic of current research [4-7]. Wang et al. [6] showed within long bars of LPBF 316L that scan strategies using shorter scan tracks reduced RS and attributed this to lower solidification shrinkage. Roehling et al. [7] observed a decrease of RS in samples with a bridge geometry manufactured by LPBF of 316L due to post-solidification heating of each layer during the build job using selective large-area diode surface heating. This method aimed to decrease the cooling rate. Each of the two publications had mainly utilized one of the two mechanisms to reduce RS: Wang et al. [6] mainly utilized the SSM, whereas Roehling et al. [7] mainly utilized the TGM. In both cases, a reduction of RS was observed. However, there is still a level of uncertainty on the magnitude of the influence of each mechanism onto the shape of the resulting RS field.

Diffraction is a well-known non-destructive method to evaluate RS [8-10]. Determining elastic strains by measuring the variation of lattice spacing provides a powerful method to identify RS. This is achieved at the surface by Lab X-ray Diffraction (XRD), up to a depth of about $5 \mu \mathrm{m}$ in metals, as well as in the bulk by Neutron Diffraction (ND) up to a depth of about a few $\mathrm{mm}$ to a few $\mathrm{cm}$ [11-13]. In this work, the bulk triaxial RS state was determined using ND and was combined with the Lab XRD biaxial RS state at the surface. This methodology allows for the mapping of the RS distribution across the complete cross-sectional plane. Such residual stress tends to be compressive in the bulk and tensile near the surface [14]. ND enables the non-destructive determination of the triaxial RS state over a complete two-dimensional (2D) plane or three-dimensional (3D) volume. Destructive methods, such as incremental or deep hole drilling, slitting, or contour method, would also yield stress depth profiles, but it would be extremely difficult to determine triaxial stress states over a complete cross-section.

To exploit the benefits of lightweight, load driven structural designs for LPBF metallic parts, it is necessary to understand RS in those parts, since their effect on fatigue life can be significant [15]. In order to understand RS, it is necessary to decouple the contributing mechanisms, especially if we aim at modelling the manufacturing process.

Therefore, this study aims at unravelling the contributions of the two mechanisms, to provide a basis for discussion on the length scale of RS introduced into parts by the TGM and the SSM. Therefore, the specimen design was chosen to provide similar solidification shrinkage, but at the same time different cooling rates without changing the volumetric energy density (VED) of specimens. Based on this design, similar RS results should be assigned to equal solidification shrinkage, whereas differences should be caused by the different cooling rates. Online monitoring by thermography during the build process was used in order to assess these cooling rates and their effect on RS formation.

The TGM is mainly related to process parameters (e.g., VED) and the SSM is mainly related to the length of shrinking scan tracks. Therefore, the results of this study might help to decide which approach is more suitable to reduce RS for a specific part design and its expected load profile.

Additionally, the results from Micro Computed Tomography $(\mu \mathrm{CT})$ and Optical Microscopy $(\mathrm{OM})$ were evaluated to link RS fields and defect distributions, with the aim to produce a holistic approach towards the analysis of the interconnection of TGM and SSM.

\section{Materials and Methods}

\subsection{Material and LPBF Processing Conditions}

Austenitic stainless steel 316L powder was processed by the commercial LPBF system SLM280 HL (SLM Solutions Group AG, Lübeck, Germany). The powder was characterised by its supplier: it has an apparent density of $4.58 \mathrm{~g} \mathrm{~cm}^{-3}$ and a mean diameter of $34.69 \mu \mathrm{m}$. The cumulative mass values of the particle size distribution are: $D_{10}=18.22 \mu \mathrm{m}, D_{50}=30.50 \mu \mathrm{m}, D_{90}=55.87 \mu \mathrm{m}$. The LPBF system uses a single $400 \mathrm{~W}$ continuous wave ytterbium fibre laser with a spot size of approx. $80 \mu \mathrm{m}$ in a focal position. The processes were conducted in an argon gas atmosphere with an oxygen content of less 
than $0.1 \%$. The parts were manufactured on a stainless steel substrate plate, which was heated up to $100{ }^{\circ} \mathrm{C}$ as a preheating temperature before the start of the build process. Two prismatic specimens of the dimension $24 \mathrm{~mm} \times 36 \mathrm{~mm} \times 24.5 \mathrm{~mm}$ were manufactured in two separate built processes. In order to remove specimens from the base plate a band saw was used. This reduced the height to a final value of $21 \mathrm{~mm}$. A specimen design of low aspect ratio was chosen for this experiment in order to prevent significant RS relaxation due to distortion after the removal from the substrate plate. Such a distortion had been reported in literature for LPBF 316L [16,17]. Although the removal from the substrate plate may have caused a degree of RS relaxation, the overall relative trend between the specimens was considered to be mainly unaffected. The specimens were placed close to the border of the base plate to fit within the field of view of the thermography camera setup. The specimens were manufactured using the following process parameters: layer thickness $t=50 \mu \mathrm{m}$, scanning velocity $v=700 \mathrm{~mm} \mathrm{~s}^{-1}$, laser power $P=275 \mathrm{~W}$, and hatch distance $h=0.12 \mathrm{~mm}$. Two different so-called border fill scanning strategies were applied, which scan along the edges of the rectangular cross sections of the parts: for one the scanning sequence starts in the centre of the part with growing rectangles towards the perimeter and the other has a converse scanning sequence (see Figure 1). The interlayer time (according to Mohr et al. [18]) was approximately $27.6 \pm 1.0 \mathrm{~s}$ due to time variations between re-coating forwards and backwards. Therefore, the total time for each build process of 490 layers added up to $3.76 \mathrm{~h}$.

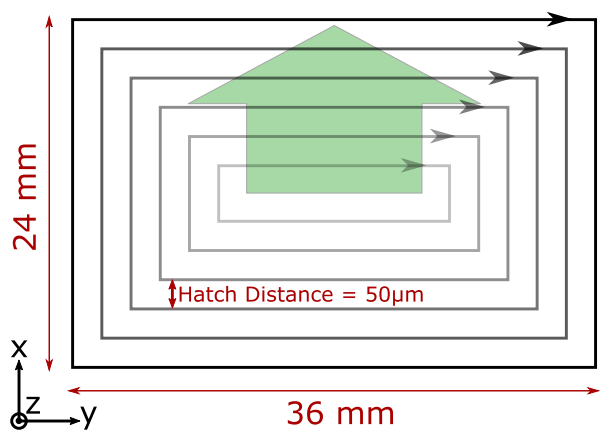

(a) $\ulcorner\overline{\boldsymbol{\Lambda}}\urcorner$ Centre to Perimeter $(\mathrm{CtP})$

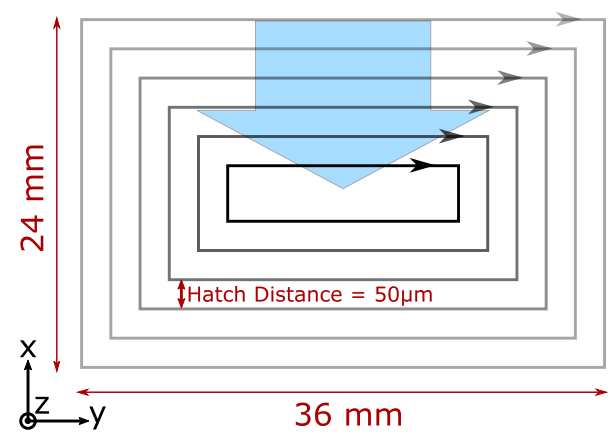

(b) $\ulcorner\bar{\nabla}\urcorner$ Perimeter to Centre (PtC)

Figure 1. Schematics of both border fill scan strategies. (a) Describes the Centre to Parameter (CtP) strategy indicated by the green arrow, while (b) shows the Parameter to Centre (PtC) scan strategy indicated by the blue arrow. The black arrows show the direction of scan of the laser around each border fill scan.

\subsection{Thermography}

An ImageIR 8300 hp camera (Infratec $\mathrm{GmbH}$, Dresden, Germany) working in the spectral range of 2-5.7 $\mu \mathrm{m}$ was used for thermographic measurements. It was mounted on top of the SLM280 HL machine's build chamber, observing the build plate through a sapphire window. The chosen subframe image had a size of $160 \mathrm{px} \times 114 \mathrm{px}$ featuring a geometric resolution on the build plate of $360 \mu \mathrm{m} \mathrm{px}{ }^{-1}$. The acquisition frame rate was set to $1000 \mathrm{~Hz}$. The camera was calibrated for black body radiation. Due to the fact that the emissivity of the used material is well below unity [19] and the process was observed through optical elements, the calibration is not valid for quantitative evaluation of the obtained thermography data. Nonetheless, assuming that the emissivity remains (approximately) constant during the build process, the obtained apparent temperatures enable comparisons within a single build process and between the two different build processes. The thermography data for the two specimens were obtained during the build process while using two different calibration ranges: $673 \mathrm{~K}$ to $1073 \mathrm{~K}$ for the $\mathrm{CtP}$ specimen $(\ulcorner\overline{\boldsymbol{\Delta}}\urcorner)$ ) and $623 \mathrm{~K}$ to $973 \mathrm{~K}$ for PtC specimen $(\ulcorner\nabla\urcorner)$. Several overlapping ranges were being tested during this experiment to find the optimum for these specimens. Values within the overlapping apparent temperature range of $673 \mathrm{~K}$ to $973 \mathrm{~K}$ can be compared between the two build processes. For quantitative evaluation of the process, it would also be necessary to address the 
additional error in temperature estimation introduced by the limited spatial resolution of $360 \mu \mathrm{m} \mathrm{px} \mathrm{x}^{-1}$. This error diminishes once the spatial temperature gradients have decreased due to lateral heat flow. These limitations are discussed in more detail by Mohr et al. [20]. Despite these limitations, qualitative analysis of the thermography data revealed results that contribute to the understanding of the presented RS results.

\subsection{Lab X-ray Diffraction}

A StressTech Xstress G3 X-ray diffraction instrument (Stresstech GmbH, Rennerod, Germany) was used in order to determine the RS distribution at the surface of the specimens according to the $\sin ^{2} \psi$-method. Based on the assumption that that principal stresses are aligned with the geometrical axes of the specimens and the normal stress component can be neglected at the surface, the RS could be calculated from the slope of the linear fit of the lattice spacings over $\sin ^{2} \psi$-plot $[9,21]$. The $\psi$-tilt was carried out in the angular range of $\psi=-45^{\circ}$ to $\psi=45^{\circ}$ in 19 steps. The specimens were tilted around two perpendicular axes, to yield two perpendicular stress components. On the $36 \mathrm{~mm}$ surface, this corresponds to seven measurement positions of the prisms' normal and longitudinal stress component (see blue circles in Figure $2 \mathrm{~b}$ ). On the $24 \mathrm{~mm}$ surface, five measurement positions correspond to the normal and transversal component of the RS distribution of the prisms. The exposure time for each acquisition was $5 \mathrm{~s}$. The 311 diffraction line at a corresponding $2 \vartheta$ angle of $152.26^{\circ}$ was acquired using a $\mathrm{Mn} \mathrm{K}_{\alpha}$ radiation source and a $2 \mathrm{~mm}$ diameter collimator. Further details of the setup were described by Thiede et al. [13]. The software Xtronic (Stresstech GmbH, Rennerod, Germany) was used for data processing. The peak fitting process was performed using the Pearson VII function and the background was fitted with a parabolic function. The diffraction elastic constants (DEC) were calculated for austenitic steel 316L based on the Eshelby-Kroener model [22]. The calculated Young's modulus of $E^{311}=184 \mathrm{GPa}$ and Poisson's ratio $v^{311}=0.294$ agree with values reported by Rangaswamy et al. [23], as well as with results from measurements and simulations of the DEC values of LPBF 316L reported by Chen et al. [24].

\subsection{Neutron Diffraction}

Stress determination by neutron diffraction (ND) was carried out at the STRESS-SPEC diffraction instrument [25] at the neutron facility FRM II in Munich, Germany (Figure 2a).

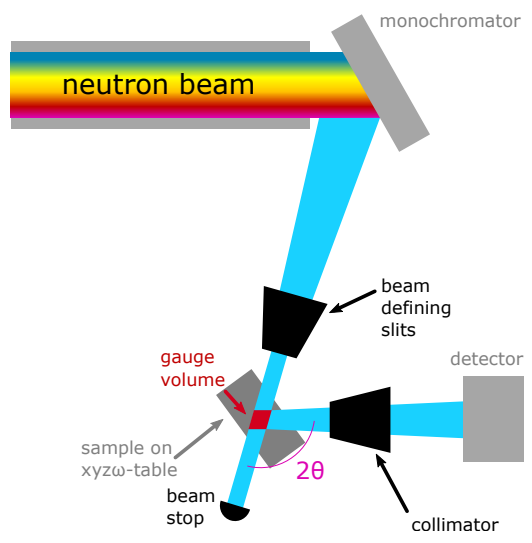

(a) principle sketch of the STRESS-SPEC beamline at FRM II, Munich

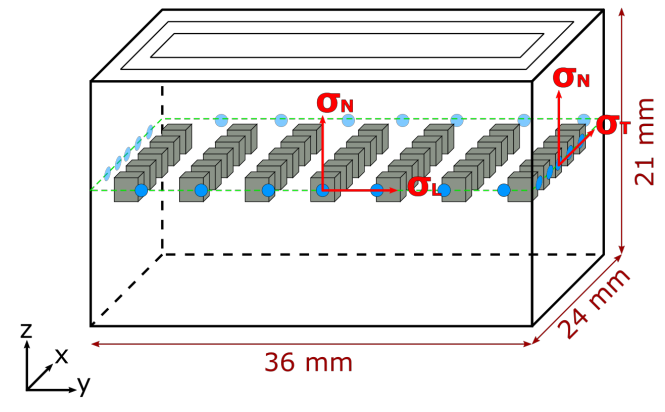

(b) map of measurement positions: blue circles (surface), grey cubes (bulk)

Figure 2. Beamline setup and measurement positions.

A bent $\mathrm{Si}_{400}$ single crystal monochromator was used to select the wavelength of $1.550 \AA$. The $\mathrm{Fe}_{311}$-peak was selected in order to characterise the RS distribution due to the low accumulation 
of inter-granular stresses reported for this reflection in conventional face-cubic-centred (fcc) iron materials [10].

To map the RS in the cross sectional plane at the mid build height of the specimen, a gauge volume of $2 \mathrm{~mm} \times 2 \mathrm{~mm} \times 2 \mathrm{~mm}$ was used in a grid of $7 \times 5$ measurement points. (see grey cubes in Figure 2b). The coordinate system is depicted in Figure $2 \mathrm{~b} . \sigma_{L}$ represents the RS along the $y$-direction, $\sigma_{T}$ along the $x$-direction and $\sigma_{N}$ along the $z$-direction, which was also the build direction.

A stress-free reference was needed to calculate strains from the measured $d^{311}$ lattice-spacing. A small cube with the size of $3 \mathrm{~mm} \times 3 \mathrm{~mm} \times 3 \mathrm{~mm}$ was sectioned from the bottom corner of a separate test build job of the PtC specimen $(\ulcorner\nabla\urcorner)$. This cube was regarded as free of Type I macro-stresses [9], due to the mechanical relaxation during sectioning. The strain can subsequently be derived from the measured $\vartheta$ angles using Bragg's law [9].

$$
\varepsilon=\frac{d^{311}-d_{0}}{d_{0}}=\frac{\sin \vartheta^{311}}{\sin \vartheta_{0}}-1
$$

Assuming that the principal geometric directions correspond with the principal stress directions Hooke's law reads as the following, as described by Holden et al. [26]:

$$
\sigma_{L, T, N}=\frac{E^{311}}{\left(1+v^{311}\right)\left(1-2 v^{311}\right)}\left[\left(1-v^{311}\right) \varepsilon_{L, T, N}+v^{311}\left(\varepsilon_{T, N, L}+\varepsilon_{N, L, T}\right)\right]
$$

The $d_{0}$ value was derived from the average of the $\vartheta^{311}$ measurements of the cube in longitudinal $(L)$, transversal $(T)$ and normal $(N)$ direction, where the normal direction corresponds to the build direction (as depicted in Figure $2 b$ ). The same DECs that were derived from the Eshelby-Kroener model were applied to both Lab XRD and ND results (see Section 2.3).

\subsection{Micro Computed Tomography}

The small reference cube for ND was studied using Micro Computed Tomography $(\mu \mathrm{CT})$ to obtain a detailed dataset of the internal defect structure. The $\mu \mathrm{CT}$ measurements were performed at a GE v l tome I $\times 180 / 300$ CT scanner (GE Sensing \& Inspection Technologies GmbH, Wunstorf, Germany) using the $180 \mathrm{kV}$ source at a voltage of $150 \mathrm{kV}$ and a current of $40 \mu \mathrm{A}$ without any metal pre-filter. A voxel size of $(3 \mu \mathrm{m})^{3}$ was achieved. The analysis of the data was performed using the commercial software VG Studio MAX version 3.2.1 (Volume Graphics GmbH, Heidelberg, Germany). A lower threshold limit of 8 voxels was used for pore detection.

\subsection{Optical Microscopy}

For Optical Microscopy (OM) investigations of the microstructure, the bottom faces of the samples were ground, polished, and etched. Emery papers with 180, 320, 600 and 1200 grits followed by clothes with $3 \mu \mathrm{m}$ and $1 \mu \mathrm{m}$ were used. For etching the Bloech \& Wedl II method [27] (a solution of $50 \mathrm{~mL} \mathrm{H}_{2} \mathrm{O}$, $50 \mathrm{~mL} \mathrm{HCl}, 0.6 \mathrm{~g} \mathrm{~K}_{2} \mathrm{~S}_{2} \mathrm{O}_{5}$ ) was applied. The microstructure was captured using a Olympus BX53M microscope with a DP74 camera module (Olympus Corporation, Tokyo, Japan). The analysis was performed using the software Olympus Stream Essentials (Olympus Corporation, Tokyo, Japan).

\section{Results}

\subsection{In-Situ Thermography}

The build jobs of both samples were supervised in-situ by thermography in order to receive more detailed information on the local variation of the temperature gradient and cooling rates. Figure $3 a, b$ display the maximum apparent temperatures at the mid-height layer.

The thermography data were averaged over 40 layers at the mid build-height to reduce noise and the influence of smoulder and spatter. In relation to the height of the specimens of $21 \mathrm{~mm}$, 
these 40 layers represent an average of the height range from $9.35 \mathrm{~mm}$ to $11.35 \mathrm{~mm}$. The number of 40 layers $(=2 \mathrm{~mm})$ was chosen, since this corresponds to the size of the used gauge volume for ND $(2 \mathrm{~mm} \times 2 \mathrm{~mm} \times 2 \mathrm{~mm})$.

The scan strategy of the PtC specimen $(\ulcorner\bar{\nabla}\urcorner)$ resulted in an increased heat accumulation in the center, compared to the CtP specimen $(\ulcorner\overline{\boldsymbol{\Delta}}\urcorner)$. This could be observed as an increase in the maximum temperature at the centre, when comparing Figure $3 \mathrm{~d}, \mathrm{c}$.

Figure $3 \mathrm{~d}$ shows the different apparent temperature values for the four sections of the plane. These differences were caused by a combination of the different surface roughness of each section and of the shadowing effects from the smoulder.

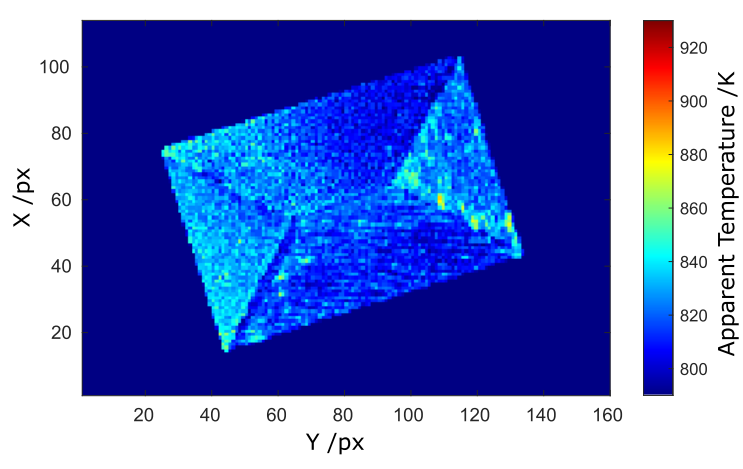

(a) $\ulcorner\overline{\boldsymbol{\Delta}}\urcorner \mathrm{CtP}$ specimen's mid-height layer

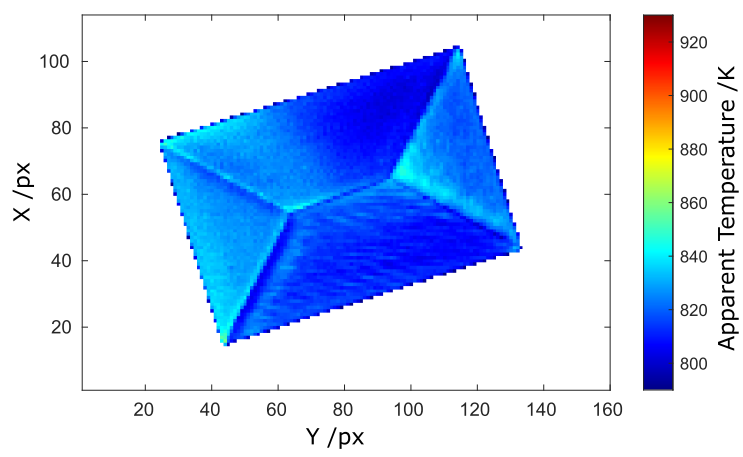

(c) $\ulcorner\overline{\boldsymbol{\Lambda}}\urcorner \mathrm{CtP}$ specimen: 40 layers at mid-height averaged

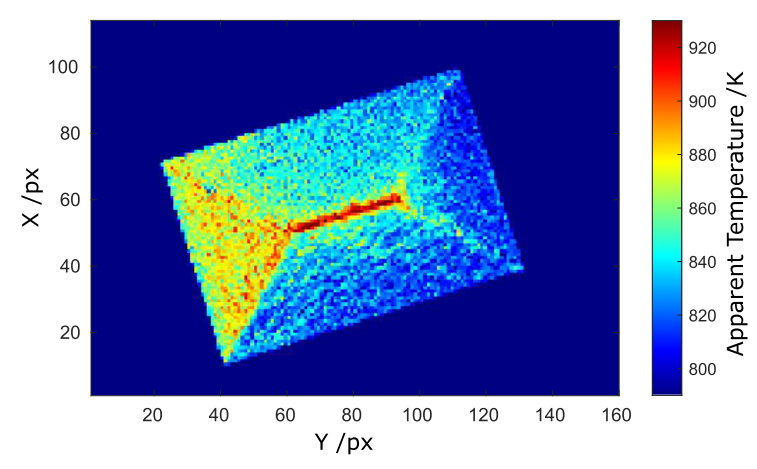

(b) $\ulcorner\bar{\nabla}\urcorner$ PtC specimen's mid-height layer

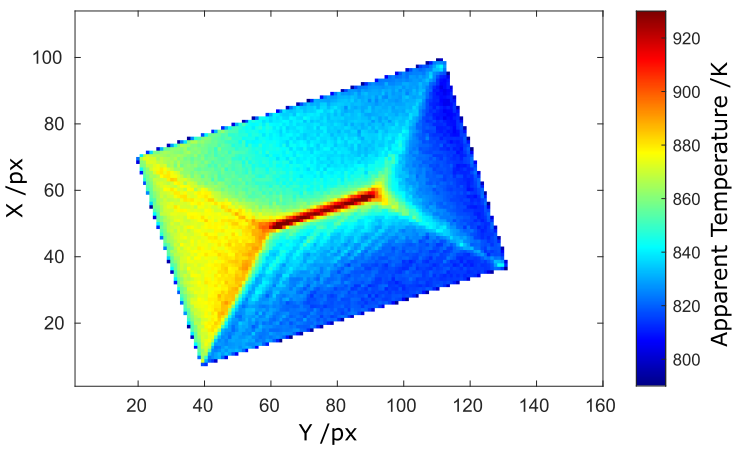

(d) $\ulcorner\bar{\nabla}\urcorner$ PtC specimen: 40 layers at mid-height averaged

Figure 3. Apparent (uncalibrated) maximum temperature of the two specimens obtained from thermography data acquired during the build process at the sample's mid build height. Each border fill scan started and ended at the bottom right hand laser turn position of the images. $(\mathbf{a}, \mathbf{b})$ display the mid-height layer, (c,d) display an average of 40 layers at the mid-height.

Figure 4 shows the cooling rate of both specimens. The cooling rate- $\mathrm{dT} / \mathrm{dt}$ was obtained by comparing two images at $t=1 \mathrm{~ms}$ and $t=2 \mathrm{~ms}$ after an apparent temperature of $700 \mathrm{~K}$ was reached for the last time at the surface. Typical times for cooling from the maximum temperature to $700 \mathrm{~K}$ were between $2 \mathrm{~ms}$ and up to $15 \mathrm{~ms}$. The cooling time of $15 \mathrm{~ms}$ was observed at the centre of the PtC specimen $(\ulcorner\bar{\nabla}\urcorner)$.

As displayed in Figure $4 \mathrm{~d}$, the PtC specimen $(\ulcorner\bar{\nabla}\urcorner)$ also featured a lower cooling rate in the centre of the plane in addition to the higher maximum temperature depicted in Figure $3 \mathrm{~d}$. The CtP specimen $(\ulcorner\overline{\boldsymbol{\Delta}}$ ) shows a low cooling rate at the edges of the specimen indicating that the surrounding metal powder served as an heat insulator for conduction, as assumed in modelling [28]. 


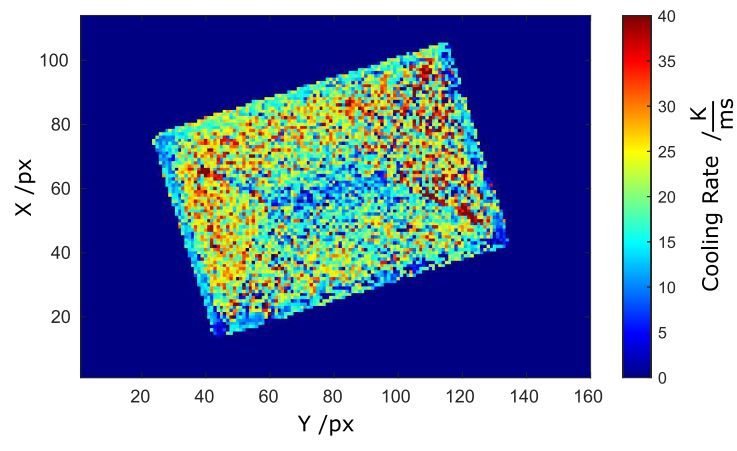

(a) $\ulcorner\overline{\boldsymbol{\Lambda}}\urcorner \mathrm{CtP}$ specimen's mid-height layer

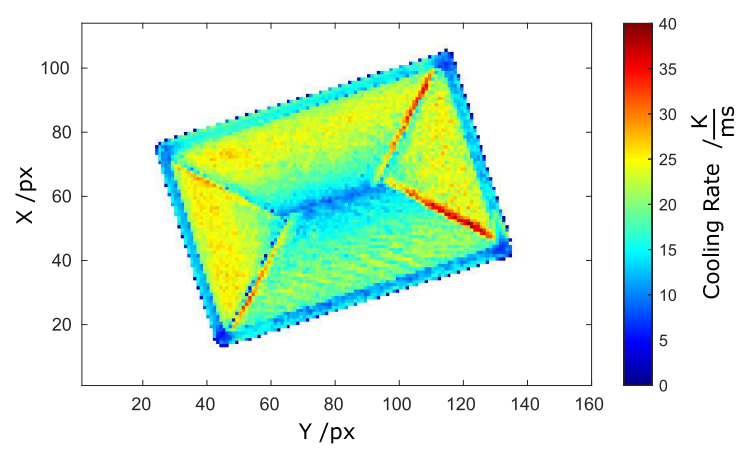

(c) $\ulcorner\overline{\boldsymbol{\Delta}}\urcorner$ CtP specimen: 40 layers at mid-height averaged

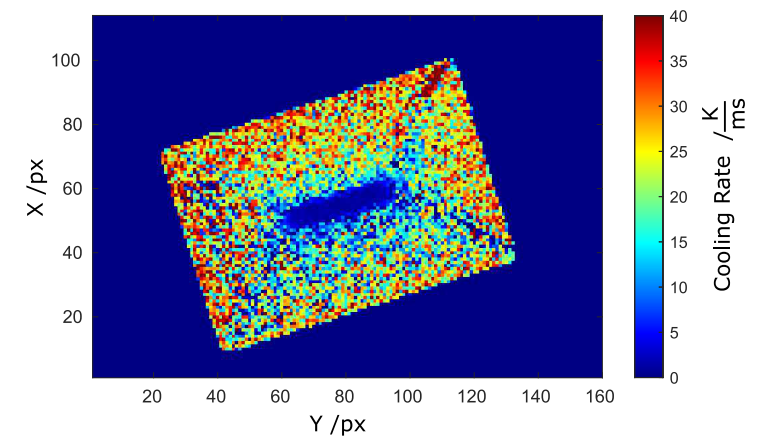

(b) $\ulcorner\bar{\nabla}\urcorner$ PtC specimen's mid-height layer

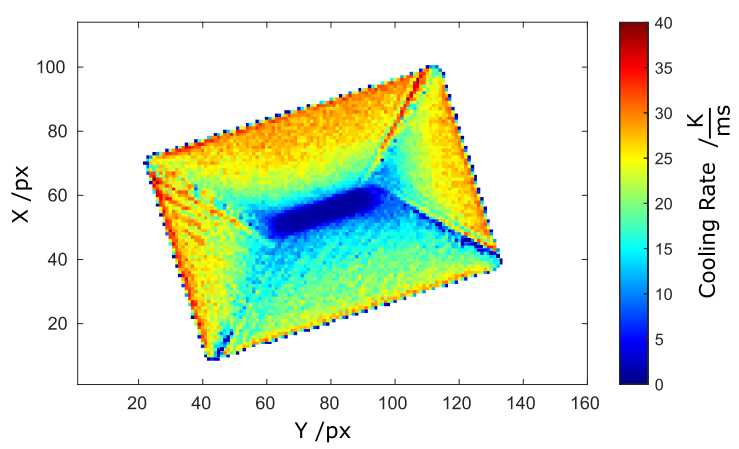

(d) $\ulcorner\nabla\urcorner$ PtC specimen: 40 layers at mid-height averaged

Figure 4. Cooling rates measured by the different between images taken at $t=1 \mathrm{~ms}$ and $t=2 \mathrm{~ms}$ after an apparent temperature of $700 \mathrm{~K}$ was observed for the last time. Thermography data for both samples was obtained during the build process at the middle of the total build height. $(\mathbf{a}, \mathbf{b})$ display the mid-height layer, $(\mathbf{c}, \mathbf{d})$ display an average of 40 layers around the middle of the total build height.

\subsection{Combined Neutron and Lab X-ray Diffraction}

The ND results (bulk RS) were combined with Lab XRD results (surface RS) to show the complete stress distribution across the full cross section of the specimens' middle plane. The contour plot function of the commercial software Origin 2018 (OriginLab Corporation, Northampton, USA), which is based on the Delaunay triangulation, was used to visualise the combined results. Figure 5 shows the combination of ND and XRD results. The RS distribution is visualised in longitudinal, transversal, and normal direction, where the normal direction corresponds to the build direction (Figure 2b). The XRD technique used only allows for the determination of stress components which are parallel to the surface (i.e., in-plane). Therefore, to visualise the third orthogonal stress component (perpendicular to the surface) in Figure 5 the following boundary condition was used: at the surfaces of the specimens corresponding to positions at $y=0 \mathrm{~mm}$ and $y=36 \mathrm{~mm}$, the value of the longitudinal stress component was assumed to $\sigma_{L}=0 \mathrm{MPa}$. For the value of the transversal stress component at $x=0 \mathrm{~mm}$ and $x=24 \mathrm{~mm}$ it was assumed $\sigma_{T}=0 \mathrm{MPa}$, since these are free surfaces in these corresponding stress directions. In general, for the two scan strategies, a similar RS distribution was observed in the longitudinal, transversal and normal direction. This distribution is characterised by compressive RS within the bulk, balanced by tensile RS at the surface. Instead, the RS distribution in the longitudinal and transversal direction of each specimen is similar in terms of shape and magnitude, the RS distribution in the normal (i.e., building) direction differed from the other directions in terms of shape and magnitude. 


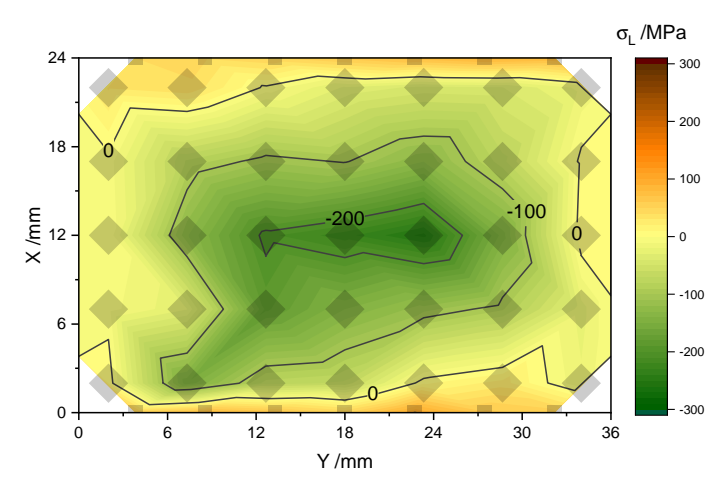

(a) $\ulcorner\overline{\boldsymbol{\Lambda}}\urcorner$ Longitudinal residual stresses (RS) component for CtP border fill strategy

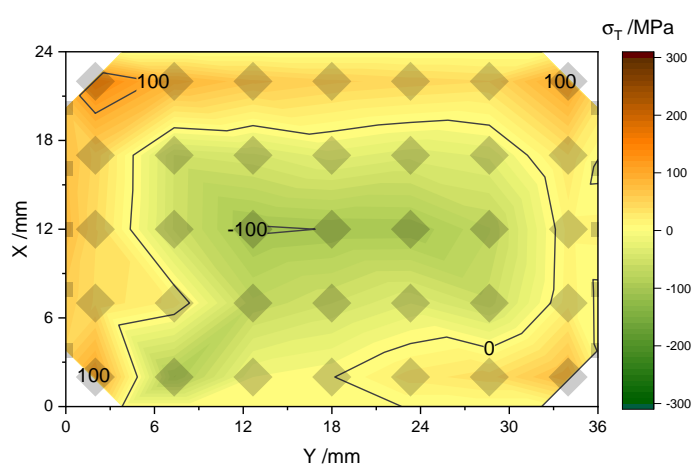

(c) $\ulcorner\overline{\boldsymbol{\Lambda}}\urcorner$ Transversal RS component for CtP border fill strategy

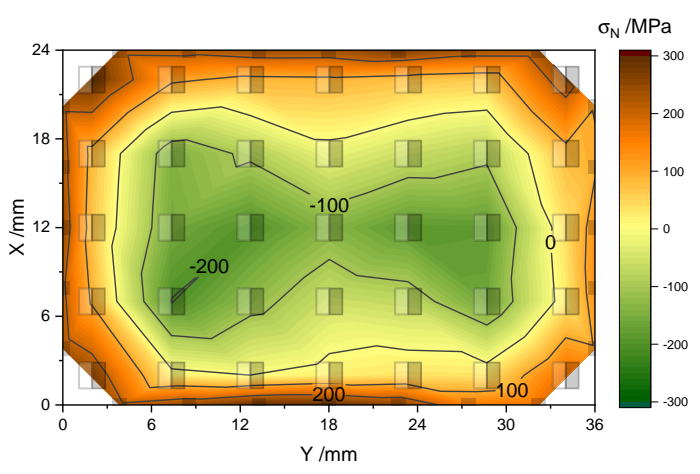

(e) $\ulcorner\overline{\boldsymbol{\Lambda}}\urcorner$ Normal RS component for $\mathrm{CtP}$ border fill strategy

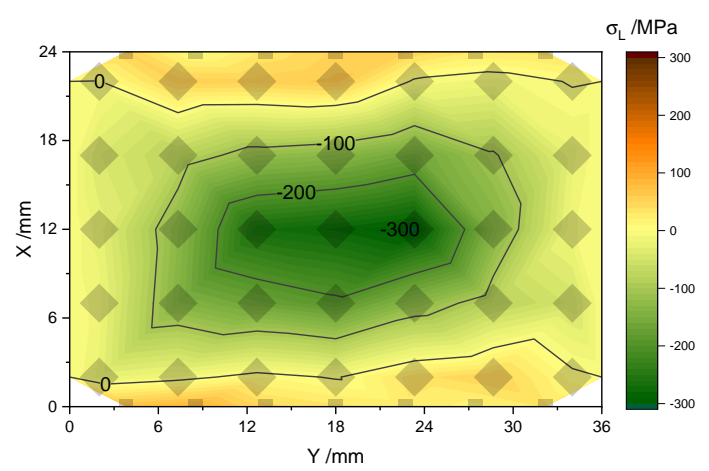

(b) $\ulcorner\bar{\nabla}\urcorner$ Longitudinal RS component for PtC border fill strategy

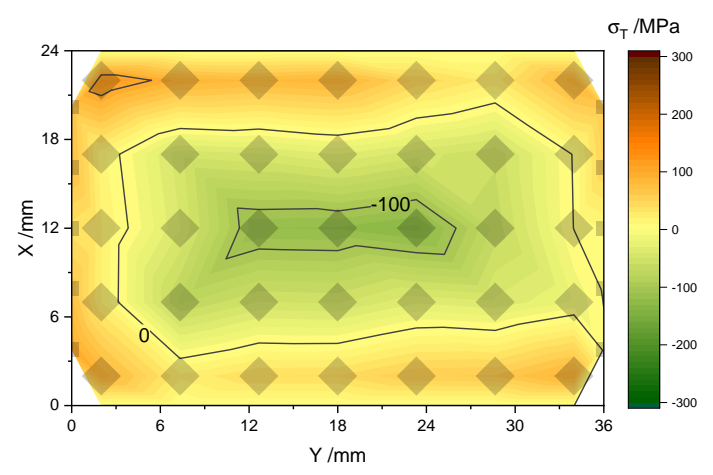

(d) $\ulcorner\bar{\nabla}\urcorner$ Transversal RS component for PtC border fill strategy

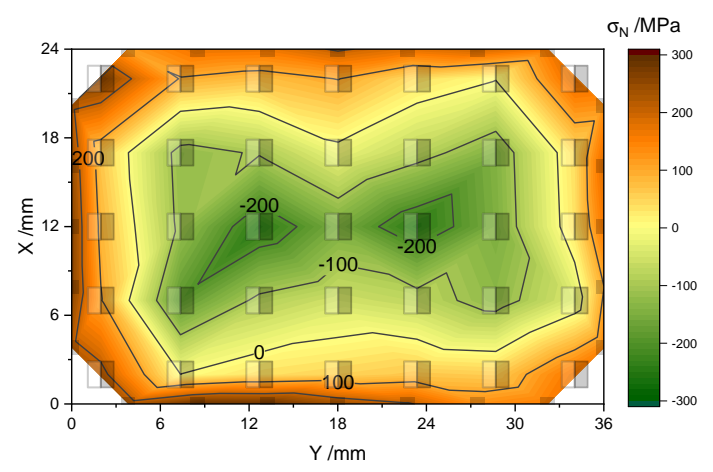

(f) $\ulcorner\bar{\nabla}\urcorner$ Normal RS component for PtC border fill strategy

Figure 5. Comparison of RS maps of the tw scan strategies including results from lab X-ray diffraction at the surface (The big semi-translucent squares in the bulk represent the almost cubic ND gauge volume (orientated differently for different stress components), whereas the small semi-translucent squares at the edges represent the lab X-ray measurement positions).

The highest magnitude of RS of each specimen (maximum tensile or maximum compressive) were observed in the normal direction. However, the $\mathrm{PtC}$ specimen $(\ulcorner\nabla\urcorner)$ displayed higher bulk compressive stresses in all three orthogonal directions. The different stress values in the normal direction, as compared to the longitudinal and transversal direction, are also reflected in the lattice spacing of the the $d_{0}$ cube. Whereas, the $d$-spacing in the longitudinal and transversal direction are relatively similar to each other, in the normal direction a larger lattice spacing was measured (see 
Table 1 ). The $d_{0}$ value was obtained from averaging the three measured directions. This averaged value was used as a stress-free lattice parameter to calculate the RS.

Table 1. Distribution of orthogonal $d$-spacing values of the reference cube.

\begin{tabular}{ccc}
\hline Orientation & $d$-Spacing & Error \\
\hline Longitudinal & $1.07449 \AA$ & $2.36 \times 10^{-5} \AA$ \\
Transversal & $1.07448 \AA$ & $2.71 \times 10^{-5} \AA$ \\
Normal & $1.07493 \AA$ & $2.41 \times 10^{-5} \AA$ \\
\hline
\end{tabular}

\subsection{Micro Computed Tomography}

The reference cube was analysed by $\mu \mathrm{CT}$ to provide an example of local defect distribution in the specimen. Because it was cut from the corner where the laser path started and ended, it represented the area where the highest amount of defects was expected. The $\mu \mathrm{CT}$ results presented in Figure 6 reveal a network of defects at the location where the laser started and ended, as well as between the hatches. Because the same scan vector was used on each hatch and layer, the projection of defects onto one plane (Figure $6 \mathrm{c}$ ) reveals the lack of fusion between neighbouring hatches. As reported in literature $[29,30]$ alternating the orientation of scan vectors between layers prevents the formation of lack of fusion defects. Because the effect of shrinkage on RS was the subject of this study, scan vectors were not altered between layers to magnify such effect.

The largest defects were situated close to the edge of the sample (Figure $6 \mathrm{~b}, \mathrm{c}$ ). A total porosity of $0.28 \%$ was observed.

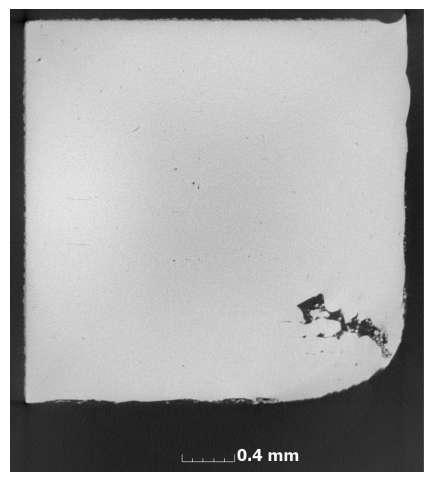

(a) slice of the cube perpendicular to the build direction

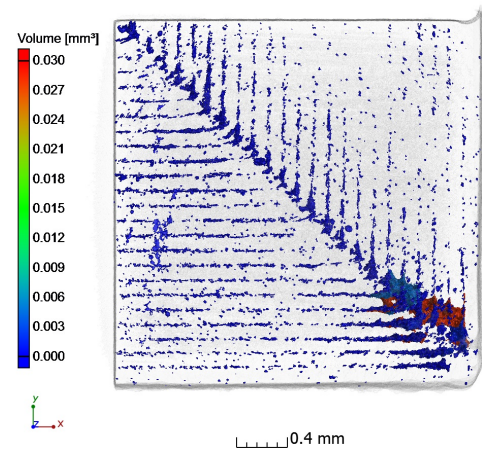

(b) $2 \mathrm{D}$ projection of the $3 \mathrm{D}$ rendered of the segmented defects within the cube perpendicular the build direction

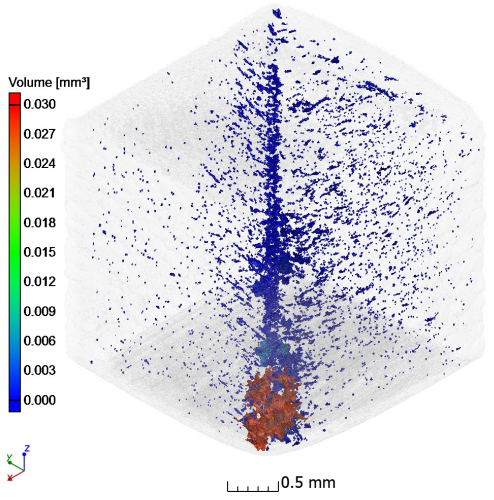

(c) 3D rendering of the segmented defects

Figure 6. $\mu \mathrm{CT}$ reconstructions of the ND reference cube sectioned from a twin PtC specimen $(\ulcorner\nabla\urcorner)$.

\subsection{Optical Microscopy}

Optical microscopy images of the polished and etched specimen's bottom surface are shown in Figure 7. Defects at the turn location of the laser are visible (Figure $7 \mathrm{~d}, \mathrm{e}$ ). The bottom surface of both specimens are expected to be less effected by heat accumulation due to the smaller build height at the time the microstructure froze, and a better heat conduction into the build plate as compared to the top layers of the specimens. Nonetheless, defects (pores and voids) were observed in both specimens at the positions, where the laser turns by $90^{\circ}$. 


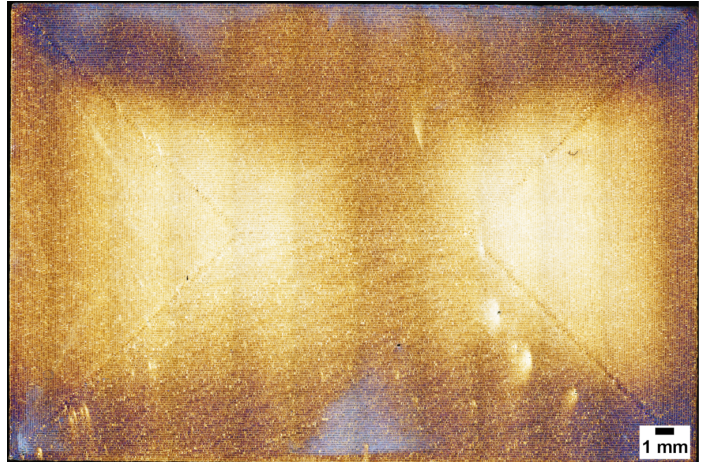

(a) $\ulcorner\overline{\boldsymbol{\Lambda}}\urcorner$ full sized image of $\mathrm{CtP}$ specimen

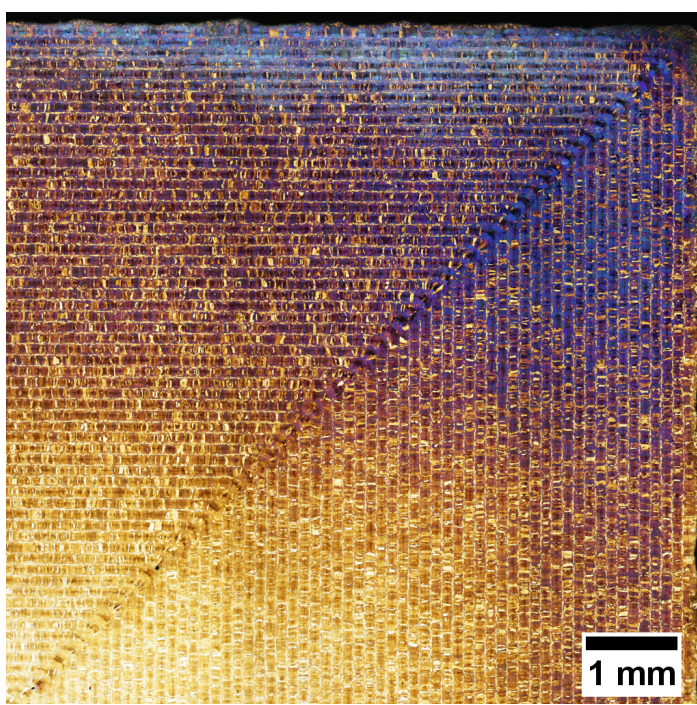

(c) $\ulcorner\overline{\boldsymbol{\Lambda}}\urcorner$ magnified upper right section of $\mathrm{CtP}$ specimen

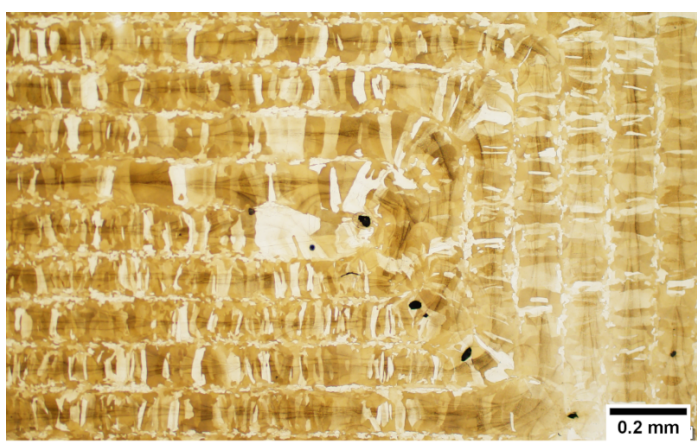

(e) $\ulcorner\overline{\boldsymbol{\Lambda}}\urcorner$ magnified section of the centre of $\mathrm{CtP}$ specimen

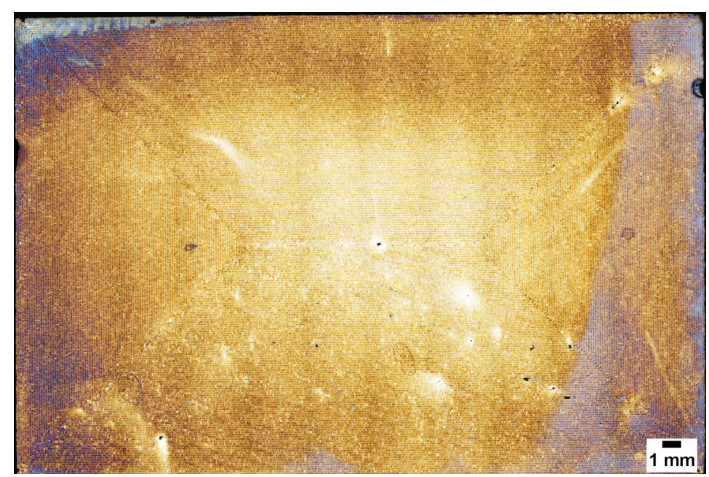

(b) $\ulcorner\bar{\nabla}\urcorner$ full sized image of PtC specimen

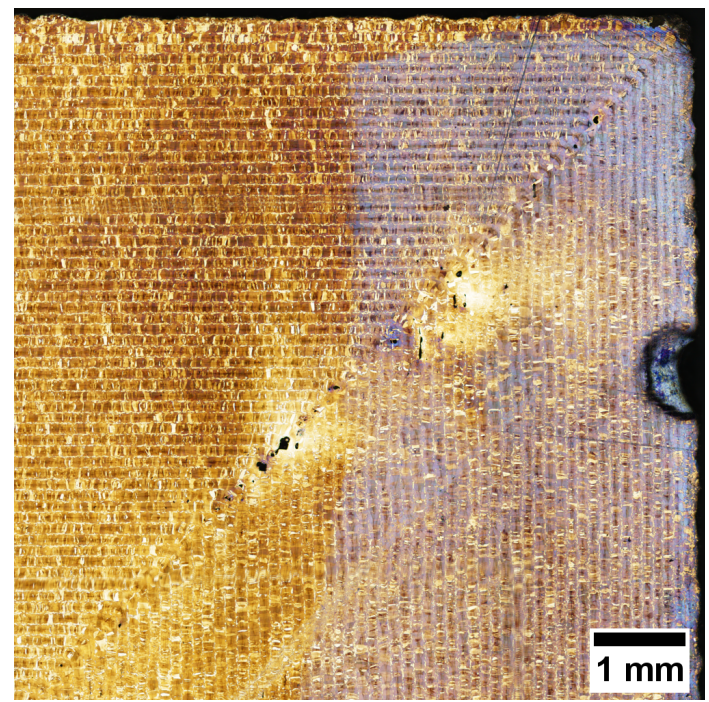

(d) $\ulcorner\nabla\urcorner$ magnified upper right section section of PtC specimen

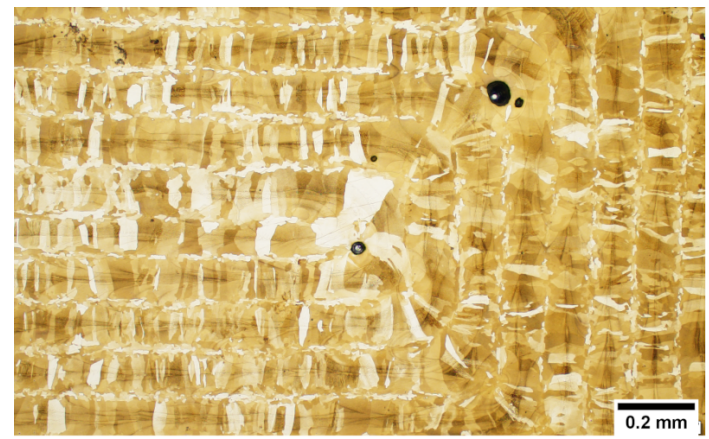

(f) $\ulcorner\bar{\nabla}\urcorner$ magnified section of the centre of $\mathrm{PtC}$ specimen

Figure 7. Optical microscopy images of the samples' bottom surface after polishing and etching.

\section{Discussion}

As mentioned in the introduction, Mercelis and Kruth [3] described two major driving mechanisms for the formation of RS in AM metallic parts made by LPBF: the temperature gradient mechanism (TGM) and the solidification shrinkage mechanism (SSM). Both of the mechanisms induced compressive stresses into the bulk material. The combined data of ND and Lab XRD showed the 
typical stress distribution pattern for metallic AM parts: compressive stresses in the bulk and tensile stresses close to the surface.

Because of the same geometric dimensions, it can be assumed that the solidification shrinkage effects in the two samples were equal. This implies that any differences in the RS distributions of the two samples should be attributed to the TGM.

According to the SSM, the induced RS distribution by solidification shrinkage depends on the length of the scanned laser tracks. The shrinkage of longer laser tracks introduces higher RS than shorter laser tracks [31]. Therefore, the longer laser tracks parallel to the $y$-axes of the specimens presented in Figure 5a-d) appear to be the main reason for the higher compressive stresses in the longitudinal stress distributions of the two specimens, as compared to the shorter laser tracks parallel to the $x$-axes, which seemed to result in lower compressive stresses for the transversal RS distributions of the two specimens.

The distribution of the normal component of the RS was assumed to be mostly independent of the SSM, since there were almost no restrictions to solidification shrinkage due to the free top surface during the layer-wise production. Therefore, the TGM was assumed to be the main mechanism to shape the RS distribution of the normal component. The RS distribution has the shape of a butterfly (see Figure 5e,f). The spikes of this butterfly pattern match the location where the laser turned by $90^{\circ}$ (see Figure 8).

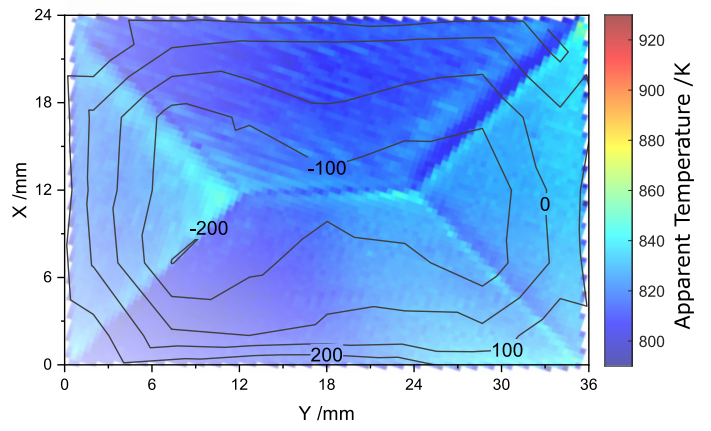

(a) $\ulcorner\overline{\boldsymbol{\Lambda}}\urcorner$ Normal stress component (Figure 5e) over thermography results (Figure 3c)

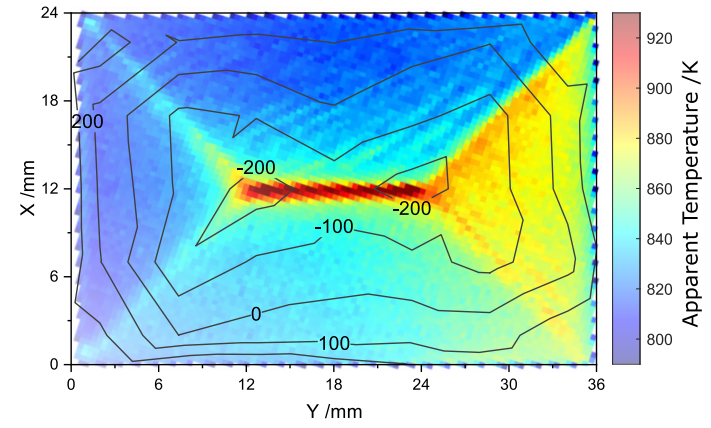

(b) $\ulcorner\bar{\nabla}\urcorner$ Normal stress component (Figure 5f) over thermography results (Figure 3d)

Figure 8. Normal (i.e., build direction) stress component (contour lines) in MPa (Figure 5e,f) overlayed with thermography results (Figure 3c,d) to highlight the compressive stresses at the laser's turn locations.

It is also observed that the normal component exhibits the highest tensile stresses (see Figure 5 and Table 2). The determined RS values are below the tensile yield strength ranges for LPBF 316L (450 MPa to $590 \mathrm{MPa}$ ) as reported by Wang et al. [32].

Table 2. Max. and min. values of the orthogonal stress components in the plane.

\begin{tabular}{cccrc}
\hline \multirow{2}{*}{ Stress Component } & \multicolumn{2}{c}{ Centre to Perimeter $\ulcorner\overline{\boldsymbol{\Lambda}}\urcorner$} & \multicolumn{2}{c}{ Perimeter to Centre $\ulcorner\bar{\nabla}\urcorner$} \\
\cline { 2 - 5 } & Max. [MPa] & Min. [MPa] & Max. [MPa] & Min. [MPa] \\
\hline$\sigma_{L}$ & $100.8 \pm 16.9$ & $-253.4 \pm 15.8$ & $86.4 \pm 10.2$ & $-304.2 \pm 15.6$ \\
$\sigma_{T}$ & $140.6 \pm 10.4$ & $-103.6 \pm 15.4$ & $122.6 \pm 11.0$ & $-134.0 \pm 15.8$ \\
$\sigma_{N}$ & $295.6 \pm 10.5$ & $-202.1 \pm 14.2$ & $290.5 \pm 10.6$ & $-245.8 \pm 19.5$ \\
\hline
\end{tabular}

Figure 8b shows that higher compressive stresses in the PtC specimen $(\ulcorner\nabla\urcorner)$ are localised close to the zone of the highest heat accumulation. This is in contrast to the CtP specimen $(\ulcorner\overline{\boldsymbol{\Lambda}}\urcorner)$, which shows lower and more evenly distributed compressive stresses in the plane (see Figure 5). The higher 
maximum temperatures at the centre of the $\mathrm{PtC}$ specimen $(\ulcorner\bar{\nabla}\urcorner)$ in combination with the slower cooling rate seem to result in larger RS in the centre of the plane as compared to the CtP specimen $(\ulcorner\overline{\boldsymbol{\Delta}}\urcorner)$. Lower contributions from the TGM to the compressive stress profile of the CtP specimen $(\ulcorner\overline{\boldsymbol{\Delta}}\urcorner)$ might be a result of the lack of heat accumulation in the centre of its plane (see Figures $3 \mathrm{c}$ and $8 \mathrm{a}$ ) and a faster cooling rate (see Figure 4c).

Line stress profiles (Figure 9) that were derived from the in-plane data presented in Figure 5 at a middle line of the plane at $x=12 \mathrm{~mm}$ emphasise the conclusion of SSM being the major mechanism to define the shape of the RS distribution. However, the TGM appears to influence the magnitude of the peak compressive stresses (see Figure 9).

It should be noted that, in Figure 9, only measured values are displayed. Therefore, the boundary condition values of $0 \mathrm{MPa}$ were excluded from the longitudinal stress profile at $y=0$ and $y=36$ (see Figure 9a). The measured bulk values close to these surfaces support the assumption of zero stress at these surfaces.

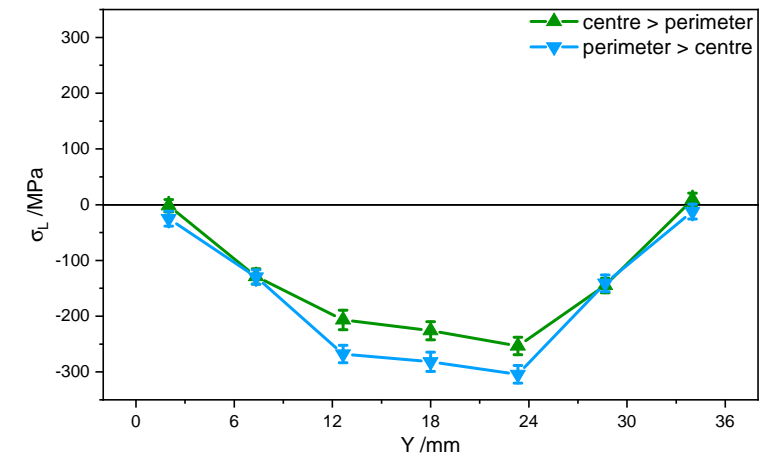

(a) Longitudinal RS component at $x=12 \mathrm{~mm}$

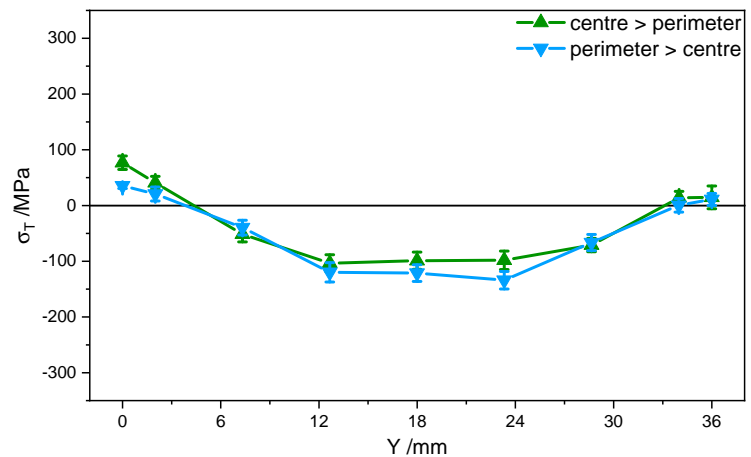

(b) Transversal RS component at $x=12 \mathrm{~mm}$

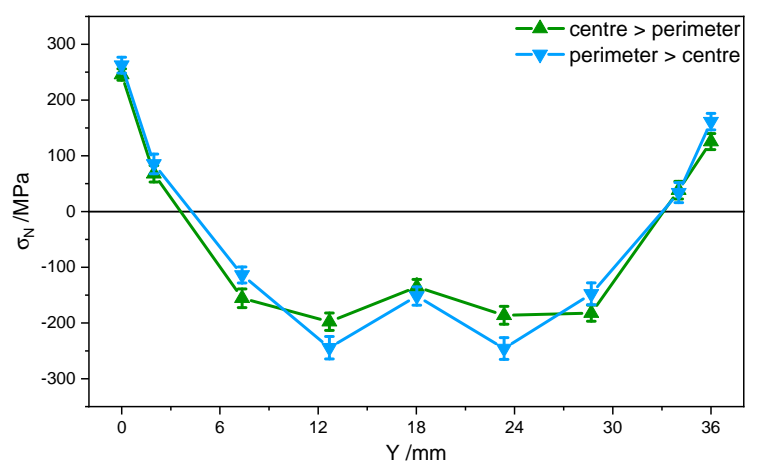

(c) Normal RS component (=build direction) at $x=12 \mathrm{~mm}$

Figure 9. Line scans in both samples for all three orthogonal directions using the combined data from ND and lab XRD.

Since the TGM does not require melting [33], it can be assumed that the compressive stress components induced by the TGM were formed in subjacent layers within the heat affected zone of the melt pool but below the layers that were remolten. It should be noted that a linear interpolation was applied to combine the surface measurement positions and the neutron data in Figure 9. Therefore, any possible sub-surface tensile peaks that had been reported by Mishurova et al. [11,34] in LPBF Ti-6Al-4V were not be taken into account in this study.

The $\mu \mathrm{CT}$ results (Figure 6) reveal a network of defects at the laser's start and stop position. OM results (Figure 7d,e) show defects at the turn locations of the scan track. These regions have been measured to be under higher tensile RS (in particular, $\sigma_{T}$ ), which is assumed to arise from the 
longitudinal and transversal solidification shrinkage, as depicted in Figure 5. Therefore, any defects in these regions might have served as micro-crack initiators. The combination of pores and tensile stress at corners could also explain why the defects observed by $\mu \mathrm{CT}$ (Figure $6 \mathrm{~b}$ ) seem to be larger towards the outer edge: the tensile stress due to solidification shrinkage increases towards the edges of the specimens due to an increase length of the laser tracks. The analysis of the optical microscopy and $\mu \mathrm{CT}$ data indicates that an unknown amount of RS might had been relaxed by micro-cracks at the laser's start and stop location.

\section{Conclusions}

Two prismatic AISI316L specimens using a border fill scan strategy were produced in order to differentiate the effect of the temperature gradient mechanism from the solidification shrinkage mechanism in AM metallic parts produced by LPBF. The following conclusions could be made:

1. A combination of surface and bulk residual stress results was needed to fully cover the (surface) tensile and (bulk) compressive regions of the in-plane stress distribution.

2. By comparing the two samples, a similar stress distribution was revealed for each of the three orthogonal directions (see Figures 5 and 9), indicating that the solidification shrinkage mechanism is the main mechanism controlling the shape of the RS distribution in these samples. The temperature gradient mechanism seems to influence the magnitude of the compressive stresses without changing the overall pattern of the stress distribution.

3. In-situ thermography results of the sample exposed from the perimeter to the centre revealed a heat accumulation, which corresponds to highly localised compressive stresses due to the temperature gradient mechanism.

\section{Outlook}

In-situ Thermography recorded a detailed data set of apparent surface temperatures and enables an analysis of cooling rates. These data can be used in future simulations in order to model the RS field at the specimens' mid height. In future studies, the RS distribution in the subsurface region might be resolved using additional techniques, such as hole drilling, slitting, X-ray with layer removal, deep hole drilling, or contour method.

Additionally, twin specimens of the two prisms will allow further experiments to study the effect on maximum values of the RS distribution, if the reference cube is cut from different positions within these twin specimens. In addition, these twins will allow a systematic $\mu \mathrm{CT}$ analysis of different positions within the two specimens, in particular to relate RS and defect distributions.

Author Contributions: Conceptualization, A.U., T.F., G.M. and S.J.A.; methodology, A.U., G.M., M.S., K.S., S.J.A., T.M., I.S.-M., T.F., M.H.; formal analysis, A.U., S.J.A., M.S., K.S.; investigation, A.U., M.S., K.S., S.J.A., T.M., I.S.-M., T.F., M.H.; writing—original draft preparation, A.U., G.M., M.S., K.S., S.J.A.; writing-review and editing, A.U., G.M., M.S., S.J.A., T.M., I.S.-M., M.H., A.E., G.B., T.F.; visualization, A.U., S.J.A.; supervision, A.E., G.B.; project administration, A.E., G.B.; funding acquisition, G.B. All authors have read and agreed to the published version of the manuscript.

Funding: This research received no external funding.

Acknowledgments: This work has been funded by the BAM Focus Area Materials project AGIL “Microstructure Development in Additively Manufactured Metallic Components: from Powder to Mechanical Failure" and ProMoAM "Process monitoring of Additive Manufacturing". We are thankful for the financial support and the fruitful cooperation with all partners. This work is based upon experiments performed at the STRESS-SPEC instrument operated by FRM II at the Heinz Maier-Leibnitz Zentrum (MLZ), Garching, Germany.

Conflicts of Interest: The authors declare no conflict of interest. The funders had no role in the design of the study; in the collection, analyses, or interpretation of data; and in the decision to publish the results. 


\section{Abbreviations}

The following abbreviations are used in this manuscript:

$\begin{array}{ll}\text { AM } & \text { Additive Manufacturing } \\ \text { FRM II } & \text { Forschungs-Neutronenquelle Heinz Maier-Leibnitz (Research Reactor Munich II) } \\ \mu C T & \text { Micro Computed Tomography } \\ \text { ND } & \text { Neutron Diffraction } \\ \text { LPBF } & \text { Laser Powder Bed Fusion } \\ \text { OM } & \text { Optical Microscopy } \\ \text { RS } & \text { Residual Stress } \\ \text { SSM } & \text { Solidification Shrinkage Mechanism } \\ \text { TGM } & \text { Temperature Gradient Mechanism } \\ \text { VED } & \text { Volumetric Energy Density } \\ \text { XRD } & \text { (Lab) X-Ray Diffraction }\end{array}$

\section{References}

1. Ngo, T.D.; Kashani, A.; Imbalzano, G.; Nguyen, K.T.; Hui, D. Additive manufacturing (3D printing): A review of materials, methods, applications and challenges. Compos. Part B Eng. 2018, 143, 172-196. [CrossRef]

2. Frazier, W.E. Metal Additive Manufacturing: A Review. J. Mater. Eng. Perform. 2014, 23, 1917-1928. [CrossRef]

3. Mercelis, P.; Kruth, J.P. Residual stresses in selective laser sintering and selective laser melting. Rapid Prototyp. J. 2006, 12, 254-265. [CrossRef]

4. Li, R.; Shi, Y.; Wang, Z.; Wang, L.; Liu, J.; Jiang, W. Densification behavior of gas and water atomized 316L stainless steel powder during selective laser melting. Appl. Surf. Sci. 2010, 256, 4350-4356. [CrossRef]

5. Miranda, G.; Faria, S.; Bartolomeu, F.; Pinto, E.; Madeira, S.; Mateus, A.; Carreira, P.; Alves, N.; Silva, F.; Carvalho, O. Predictive models for physical and mechanical properties of 316L stainless steel produced by selective laser melting. Mater. Sci. Eng. A 2016, 657, 43-56. [CrossRef]

6. Wang, D.; Wu, S.; Yang, Y.; Dou, W.; Deng, S.; Wang, Z.; Li, S. The Effect of a Scanning Strategy on the Residual Stress of 316L Steel Parts Fabricated by Selective Laser Melting (SLM). Materials 2018, 11, 1821. [CrossRef]

7. Roehling, J.D.; Smith, W.L.; Roehling, T.T.; Vrancken, B.; Guss, G.M.; McKeown, J.T.; Hill, M.R.; Matthews, M.J. Reducing residual stress by selective large-area diode surface heating during laser powder bed fusion additive manufacturing. Addit. Manuf. 2019, 28, 228-235. [CrossRef]

8. Bacon, G. Neutron Diffraction; Clarendon Press: Oxford, UK, 1975. [CrossRef]

9. Withers, P.; Bhadeshia, H. Residual stress. Part 1-Measurement techniques. Mater. Sci. Technol. 2001, 17, 355-365. [CrossRef]

10. Hutchings, M.; Withers, P.; Holden, T.; Lorentzen, T. Introduction to the Characterization of Residual Stress by Neutron Diffraction; CRC Press: Boca Raton, FL, USA, 2005. [CrossRef]

11. Mishurova, T.; Cabeza, S.; Artzt, K.; Haubrich, J.; Klaus, M.; Genzel, C.; Requena, G.; Bruno, G. An Assessment of Subsurface Residual Stress Analysis in SLM Ti-6Al-4V. Materials 2017, 10, 348. [CrossRef]

12. Nadammal, N.; Cabeza, S.; Mishurova, T.; Thiede, T.; Kromm, A.; Seyfert, C.; Farahbod, L.; Haberland, C.; Schneider, J.A.; Portella, P.D.; et al. Effect of hatch length on the development of microstructure, texture and residual stresses in selective laser melted superalloy Inconel 718. Mater. Des. 2017, 134, 139-150. [CrossRef]

13. Thiede, T.; Cabeza, S.; Mishurova, T.; Nadammal, N.; Kromm, A.; Bode, J.; Haberland, C.; Bruno, G. Residual Stress in Selective Laser Melted Inconel 718: Influence of the Removal from Base Plate and Deposition Hatch Length. Mater. Perform. Charact. 2018, 7, 717-735. [CrossRef]

14. Wu, A.S.; Brown, D.W.; Kumar, M.; Gallegos, G.F.; King, W.E. An Experimental Investigation into Additive Manufacturing-Induced Residual Stresses in 316L Stainless Steel. Metall. Mater. Trans. A 2014, 45, 6260-6270. [CrossRef]

15. Riemer, A.; Leuders, S.; Thoene, M.; Richard, H.; Troester, T.; Niendorf, T. On the fatigue crack growth behavior in 316L stainless steel manufactured by selective laser melting. Eng. Fract. Mech. 2014, 120, 15-25. [CrossRef] 
16. Vrancken, B.; Wauthlé, R.; Kruth, J.P.; Van Humbeeck, J. Study of the influence of material properties on residual stress in selective laser melting. In Proceedings of the Solid Freeform Fabrication Symposium, Austin, TX, USA, 12-14 August 2013; pp. 393-407.

17. Wang, D.; Yang, Y.; Yi, Z.; Su, X. Research on the fabricating quality optimization of the overhanging surface in SLM process. Int. J. Adv. Manuf. Technol. 2013, 65, 1471-1484. [CrossRef]

18. Mohr, G.; Altenburg, S.J.; Hilgenberg, K. Effects of inter layer time and build height on resulting properties of 316L stainless steel processed by laser powder bed fusion. Addit. Manuf. 2020, 32, 101080. [CrossRef]

19. Hunnewell, T.S.; Walton, K.L.; Sharma, S.; Ghosh, T.K.; Tompson, R.V.; Viswanath, D.S.; Loyalka, S.K. Total Hemispherical Emissivity of SS 316L with Simulated Very High Temperature Reactor Surface Conditions. Nucl. Technol. 2017, 198, 293-305. [CrossRef]

20. Mohr, G.; Altenburg, S.J.; Ulbricht, A.; Heinrich, P.; Baum, D.; Maierhofer, C.; Hilgenberg, K. In-Situ Defect Detection in Laser Powder Bed Fusion by Using Thermography and Optical Tomography-Comparison to Computed Tomography. Metals 2020, 10, 103. [CrossRef]

21. Macherauch, E.; Mueller, P. Das sin2Psi-Verfahren der roentgenographischen Spannungsmessung. Z. Angew. Phys. 1961, 13, 305-312.

22. Kroener, E. Berechnung der elastischen Konstanten des Vielkristalls aus den Konstanten des Einkristalls. Z. Phys. 1958, 151, 504-518. [CrossRef]

23. Rangaswamy, P.; Griffith, M.; Prime, M.; Holden, T.; Rogge, R.; Edwards, J.; Sebring, R. Residual stresses in LENS (R) components using neutron diffraction and contour method. Mater. Sci. Eng. A 2005, 399, 72-83. [CrossRef]

24. Chen, W.; Voisin, T.; Zhang, Y.; Florien, J.B.; Spadaccini, C.M.; McDowell, D.L.; Zhu, T.; Wang, Y.M. Microscale residual stresses in additively manufactured stainless steel. Nat. Commun. 2019, 10, 4338. [CrossRef] [PubMed]

25. Hofmann, M.; Gan, W.; Rebelo-Kornmeier, J. STRESS-SPEC: Materials science diffractometer. J. Large-Scale Res. Facil. JLSRF 2015, 1, 6. [CrossRef]

26. Holden, T.M.; Clarke, A.P.; Holt, R.A. Neutron diffraction measurements of intergranular strains in MONEL-400. Metall. Mater. Trans. A 1997, 28, 2565-2576. [CrossRef]

27. Weck, E.; Leistner, E. Metallographische Anleitung zum Farbätzen nach dem Tauchverfahren.—3: Nichteisenmetalle, Hartmetalle und Eisenwerkstoffe, Nickel-Basis- und Kobalt-Basis-Legierungen = Metallographic Instructions for Colour Etching by Immersion.-3: Non-Ferrous Metals, Cemented Carbides and Ferrous Metals, Nickel-Base and Cobalt-Base Alloys; Deutscher Verlag für Schweisstechnik: Duesseldorf, Germany, 1986.

28. Denlinger, E.R.; Gouge, M.; Irwin, J.; Michaleris, P. Thermomechanical model development and in situ experimental validation of the Laser Powder-Bed Fusion process. Addit. Manuf. 2017, 16, 73-80. [CrossRef]

29. Thijs, L.; Verhaeghe, F.; Craeghs, T.; Van Humbeeck, J.; Kruth, J.P. A study of the microstructural evolution during selective laser melting of Ti-6Al-4V. Acta Mater. 2010, 58, 3303-3312. [CrossRef]

30. Yadroitsev, I.; Thivillon, L.; Bertrand, P.; Smurov, I. Strategy of manufacturing components with designed internal structure by selective laser melting of metallic powder. Appl. Surf. Sci. 2007, 254, 980-983. [CrossRef]

31. Bo, Q.; Yu-sheng, S.; Qing-song, W.; Hai-bo, W. The helix scan strategy applied to the selective laser melting. Int. J. Adv. Manuf. Technol. 2012, 63, 631-640. [CrossRef]

32. Wang, Y.M.; Voisin, T.; McKeown, J.T.; Ye, J.; Calta, N.P.; Li, Z.; Zeng, Z.; Zhang, Y.; Chen, W.; Roehling, T.T.; et al. Additively manufactured hierarchical stainless steels with high strength and ductility. Nat. Mater. 2018, 17, 63-71. [CrossRef]

33. Kruth, J.; Froyen, L.; Van Vaerenbergh, J.; Mercelis, P.; Rombouts, M.; Lauwers, B. Selective laser melting of iron-based powder. J. Mater. Process. Technol. 2004, 149, 616-622. [CrossRef]

34. Mishurova, T.; Artzt, K.; Haubrich, J.; Requena, G.; Bruno, G. Exploring the Correlation between Subsurface Residual Stresses and Manufacturing Parameters in Laser Powder Bed Fused Ti-6Al-4V. Metals 2019, 9, 261. [CrossRef]

(C) 2020 by the authors. Licensee MDPI, Basel, Switzerland. This article is an open access article distributed under the terms and conditions of the Creative Commons Attribution (CC BY) license (http:/ / creativecommons.org/licenses/by/4.0/). 